\title{
PERFORMANCE OF GLUCOMANNAN-ALGINATE COMBINATION AS A pH SENSITIVE EXCIPIENT OF VITAMIN C ENCAPSULATION USING GELATION METHOD
}

\author{
DYAH HESTI WARDHANI ${ }^{*}$, HERI CAHYONO ${ }^{1}$, NITA ARYANTI ${ }^{1}$ \\ ${ }^{1}$ Chemical Engineering Department, Faculty of Engineering, Diponegoro University, Jl. Prof. Soedarto, SH, Tembalang-Semarang, \\ Indonesia \\ Email: dhwardhani@che.undip.ac.id \\ Received: 15 Jul 2018, Revised and Accepted: 30 Jan 2019
}

\begin{abstract}
Objective: This research aimed to develop pH-sensitive vitamin C encapsulation using a combination of biodegradable glucomannan and alginate as an excipient.

Methods: Gelation of the excipient was developed by dropping the matrix into the $\mathrm{CaCl}_{2}$ solution to obtain beads. Various ratios of glucomannanalginate $(1: 0,1: 1,1: 3,3: 1$ and $0: 1, \mathrm{~g} / \mathrm{g})$, vitamin $C$ concentrations $(1,3$ and $5 \%$ of total excipient) and excipient preparation methods (mixed glucomannan-alginate matrix, glucomannan beads coated with alginate and alginate beads coated with glucomannan) were selected as variables. Entrapment efficiency of encapsulation and the release of vitamin $\mathrm{C}$ were determined at $\mathrm{pH} 1.2$ and 6.8 which represent the $\mathrm{pH}$ of the stomach and the small intestine liquid, respectively.
\end{abstract}

Results: Encapsulation of 3\% vitamin C using 1:1 (g/g) glucomannan-alginate showed the most efficient matrix. This ratio also had lower released of vitamin $\mathrm{C}$ in $\mathrm{pH} 1.2$ compared to that in $\mathrm{pH}$ 6.8. Coating the glucomannan bead with alginate showed better ability in encapsulating vitamin $\mathrm{C}$. Combination excipient, as well as the addition of the vitamin C, increased the peak absorbance of the functional groups. The surface morphology of the encapsulation bead depended on the preparation method.

Conclusion: An equal ratio of glucomannan and alginate $(1: 1, \mathrm{~g} / \mathrm{g})$ which encapsulated $3 \%$ vitamin $\mathrm{C}$ showed the most efficient encapsulation as well as lower released vitamin $\mathrm{C}$ in $\mathrm{pH} 1.2$ compared to that in $\mathrm{pH}$ 6.8. Higher efficiency was observed in encapsulating vitamin $\mathrm{C}$ using glucomannan which was coated with alginate.

Keywords: Alginate, Biodegradable polymer, Encapsulation, Excipient, Glucomannan, Matrix, pH-sensitive, Vitamin C

(C) 2019 The Authors. Published by Innovare Academic Sciences Pvt Ltd. This is an open access article under the CC BY license (http://creativecommons.org/licenses/by/4.0/) DOI: http://dx.doi.org/10.22159/ijap.2019v11i2.28519

\section{INTRODUCTION}

Vitamin $\mathrm{C}$ is an indispensable nutrient required to retain the physiological process of human [1]. It is, however, a very unstable compound and easily degraded when exposed to ambient temperature, oxygen and light $[1,2]$. Humans do not synthesize vitamin $\mathrm{C}$ due to the absence of enzyme L-gulonolactone oxidase. Therefore, they depend upon exogenous sources of vitamin C such as fruits and supplements [3]. International authorities suggest the Recommended Daily Intake (RDI) for adults ranging from 100-120 $\mathrm{mg} / \mathrm{d}$ to $1000 \mathrm{mg} / \mathrm{d}$, the prudent limit. The absorption of this vitamin is dose-dependent, in which $80-90 \%$ of $30-180 \mathrm{mg} / \mathrm{d}$ from the intake is absorbed in the small intestine, and the rest mainly excretes in the urine. The absorption falls to less than $50 \%$ at doses above $1000 \mathrm{mg} / \mathrm{d}$ [4]. Hence, it is necessary to maintain low dose availability of this vitamin in the intestine to maximize the absorption.

Since it is absorbed in small intestine, the vitamin $\mathrm{C}$ encapsulation should pass through the stomach (pH 1-2.5) in order to reach and absorbed in the small intestine ( $\mathrm{pH}$ 6.6-7.5) to release the vitamin $\mathrm{C}$ [5]. Considering the dose-dependent absorption efficiency of the gastrointestinal, the encapsulation excipient should allow controlling vitamin $\mathrm{C}$ release at a specific rate as well as the $\mathrm{pH}$ sensitive [6]. Hence, it is necessary to design the encapsulation and controlled release excipient which $\mathrm{pH}$-dependent to protect and successfully deliver vitamin $\mathrm{C}$ to the absorption site at the small intestine with the right dose. The real challenge in the development of an oral controlled-release drug delivery system is not only maintaining the sustainability of the drug, but also to prolong the presence of the drug within the gastrointestinal tract (GIT) until all the drug is completely released at the desired period [7].

Encapsulation vitamin $\mathrm{C}$ has been reported using chitosan $[1,8]$ and its combination with alginate [9]. Due to the heat gel-forming ability [10] and the unhydrolyzed property in the stomach [11], a safe glucomannan meets a potential candidate for excipient of vitamin C. However, glucomannan solubility needs to be modified to deliver and control the release of vitamin $\mathrm{C}$ which is pH-responsive. A combination matrix of native glucomannan and alginate has been reported to increase the loading efficiency of insulin but reduce the release rate at $\mathrm{pH} 7.4$ [12]. Moreover, this blending matrix also has higher water hydration at $\mathrm{pH} 7.4$ solution than that at $0.1 \mathrm{~N} \mathrm{HCl}$ solution. This condition fits to support glucomannan as an excipient for vitamin C controlled release. It is expected that combination between glucomannan and alginate as excipient brings out the best performance as a vitamin C controlled release. This work aimed to prepare $\mathrm{pH}$-sensitive matrix of vitamin $\mathrm{C}$ controlled release using a combination of glucomannan and alginate. Encapsulation efficiency and its release performance of vitamin $\mathrm{C}$ were determined. The basic innovation of this research was to utilize the blending matrix of glucomannan and alginate to support the $\mathrm{pH}$-sensitive matrix of vitamin C controlled release.

\section{MATERIALS AND METHODS}

\section{Materials}

Glucomannan (80\%), alginate (food grade) and vitamin C were bought from a local seller (Multi Kimia Raya Nusantara, SemarangIndonesia). $\mathrm{CaCl}_{2}, \mathrm{HCl}$, phosphate buffer $\mathrm{pH} 6.8$ were provided by Merck Indonesia.

\section{Encapsulation}

Three methods of matrix preparations were determined. In the first method, a certain ratio of glucomannan and alginate was placed in Erlenmeyer and diluted with distilled water to $200 \mathrm{ml}$. The sol was stirred at $300 \mathrm{rpm}$ for $15 \mathrm{~min}$. Vitamin $\mathrm{C}$ was added to the solution as designed $(300 \mathrm{mg})$. The mixture was dropped into a stirred $\mathrm{CaCl}_{2}$ solution $(0.2 \mathrm{~N}, 100 \mathrm{ml})$ using a syringe. After one h, the beads were collected and freeze-dried. The bead was subject to encapsulation performance analysis. 
The second and the third methods of encapsulation preparations were conducted to observe the effect of the coating of vitamin C bead on its characteristics. An excipient ratio obtained from the first method which provided the highest entrapment efficiency was used to evaluate the coating effect. A sole matrix, either glucomannan or alginate, and vitamin $\mathrm{C}$ were diluted together in $200 \mathrm{ml}$ distilled water. After dropping in the $\mathrm{CaCl}_{2}$ solution, the beads were collected and dried. These dried beads were subsequently suspended to 200 $\mathrm{ml}$ of the other sole excipient solution and followed with the dropping process. The beads were collected and freeze-dried. All the methods were repeated three times.

\section{Vitamin C entrapment efficiency}

Entrapment efficiency was defined as the amount of vitamin $\mathrm{C}$ that successfully entrapped in the excipient. The bead $(3 \mathrm{mg})$ was diluted with $10 \mathrm{ml}$ of distilled water. After centrifugation, the supernatant was read at $266 \mathrm{~nm}$ of spectrophotometer UV-Vis. The absorbance was compared to vitamin $C$ standard curve. The efficiency was calculated base on the actual amount of vitamin $\mathrm{C}$ found in the bead $(L)$ divided by the amount of vitamin $C$ added in the encapsulation process $(L o)(1)$.

$$
\text { Entrapment efficiency of vitamin } \mathrm{C}=\frac{L}{L 0} \times 100 \% \text {. }
$$

\section{The release of vitamin C}

The release of vitamin C was modified from the method of Desai $e t$ al. [13]. The release was determined at two-pH solutions of $37{ }^{\circ} \mathrm{C}$ and stirrer at $50 \mathrm{rpm}$. The bead (30 mg) was diluted in $\mathrm{pH} 1.2$ of $\mathrm{HCl}$ solution $(8 \mathrm{ml}, 0.1 \mathrm{M})$ which represent $\mathrm{pH}$ of stomach liquid. The same weight of the bead was diluted in the phosphate buffer solution ( $\mathrm{pH}$ 6.8) which represent the small intestine liquid. One $\mathrm{ml}$ of each solution was taken and diluted necessarily before the absorbance reading using spectrophotometer UV-VIS at $266 \mathrm{~nm}$. The concentration of vitamin C was compared to the standard curve of vitamin C. The release of vitamin C represents an accumulation of released vitamin $\mathrm{C}$ in a particular period.

\section{Functional groups and morphology}

The functional groups and surface morphology of the bead were determined using IR Prestige Shimadzu and FEI Inspect S50, respectively. The peaks of the groups were assigned with the literature data. The surface morphology was observed in a certain magnification.

\section{RESULTS AND DISCUSSION}

Since vitamin $\mathrm{C}$ has a high solubility, the excess supply of this vitamin is discharged from the human body [14]. On the other hand, the human body lack of enzyme L-gulonolactone oxidase which produced vitamin C [15]. Hence, vitamin C needs to be encapsulated to manage its presence in the body. In this study, a combination of glucomannan and alginate was used as an encapsulant of vitamin C.

In this work, the ratio of glucomannan and alginate $(1: 0,1: 1,1: 3,3: 1$ and $0: 1, \mathrm{~g} / \mathrm{g})$, the concentration of vitamin $\mathrm{C}(1,3$ and $5 \%$ of total excipient weight) and the encapsulation method preparation were selected as variables. The encapsulated vitamin $\mathrm{C}$ was subject to the efficiency of encapsulation and the release of vitamin $\mathrm{C}$, which determined at $\mathrm{pH} 1.2$ and 6.8 .

This work was conducted in 2 stages. In the first stage where the effect of the ratio of encapsulant and concentration of vitamin $C$ was studied, both excipients and vitamin $\mathrm{C}$ were blended followed by the encapsulation process by dropping in $\mathrm{CaCl}_{2}$ solution. The expected output of the first stage was the ratio and concentration of vitamin C which had high efficiency as well as supported the vitamin $\mathrm{C}$ protection in $\mathrm{pH}$ stomach and delivered the vitamin into the intestine sites.

The second stage focused on the effect of encapsulation preparation. Firstly, vitamin $\mathrm{C}$ was blended with one of the encapsulant material followed by dropping to $\mathrm{CaCl}_{2}$ solution and drying process. The obtained beads subsequently were suspended to the other encapsulant suspension before dropping to the $\mathrm{CaCl}_{2}$ prior to be freeze-dried to obtain the encapsulated vitamin C.
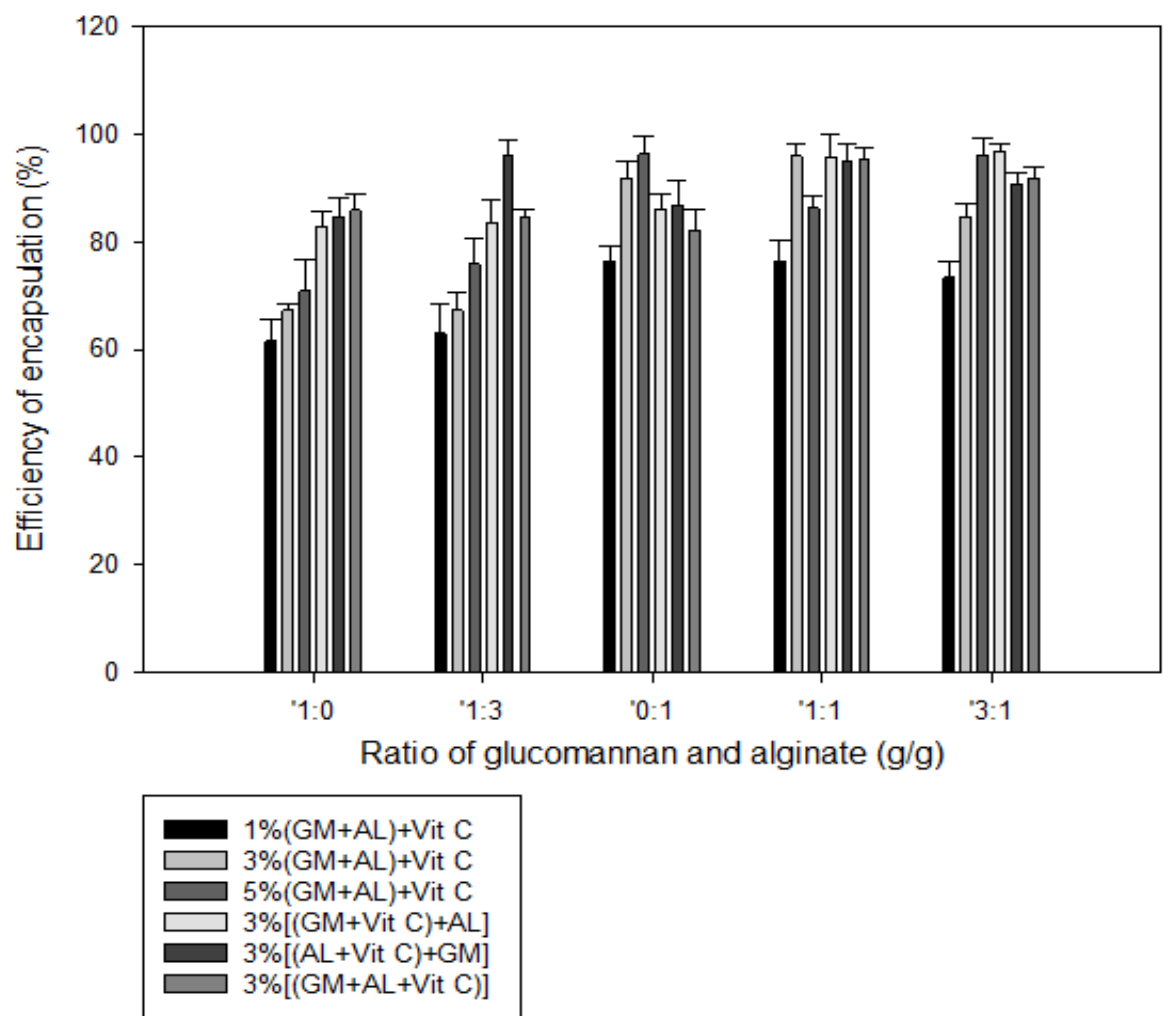

Fig. 1: Effect of vitamin C concentration, the ratio of glucomannan-alginate and preparation methods on the encapsulation efficiency, *results are expressed as mean $\pm \mathrm{SD}, \mathrm{n}=3$ (GM=glucomannan, $\mathrm{AL}=$ alginate) 


\section{Entrapment efficiency}

The efficiency was described as the ability of the excipient to trap the active compound compared to the active compound added during the loading. Fig. 1 shows the ratio of combination excipient and the concentration of vitamin $\mathrm{C}$ affected the efficiency. The use of sole glucomannan as the excipient $(1: 0, \mathrm{~g} / \mathrm{g})$ resulted in lower efficiency. The sole alginate $(0: 1, \mathrm{~g} / \mathrm{g})$ showed higher efficiency than that of the sole glucomannan $(1: 0, \mathrm{~g} / \mathrm{g})$ in encapsulating $3 \%$ vitamin C. Native glucomannan did not form a gel. However, the glucomannan gel was induced by the alkaline condition. In this work, the glucomannan solution was dropped into $\mathrm{CaCl}_{2}$ solution which could help in creating the gel by changing the glucomannan chain from semi-crimping to self-crimping. This crimping leads to self-aggregation between the molecules [16]. The gel properties themselves subject to deacetylation degree. Meanwhile, the alginate forms the beads prior to dropping into $\mathrm{CaCl}_{2}$ solution which used as a crosslinking agent in this study. Alginate is negatively charged of polysaccharide which able to react with divalent cations, in this case, is $\mathrm{Ca}^{2+}$ ions of $\mathrm{CaCl}_{2}$ solution to produce a strong gel [17]. It seems that the gelation condition of this study implied better bead properties on alginate than that on glucomannan. Hence, more vitamin $\mathrm{C}$ was trapped in the gel as the alginate was crosslinked with a divalent cation to form a bead.

Fig. 1 shows changing the ratio of the matrix impacted to the efficiency. Changing the ratio of the excipient created different viscosities of the excipient, as also reported by Wardhani et al. [18]. Variation in viscosity could affect the gel formation of the excipients which in turn influences the size of the bead as well as the capability of the matrix to entrap the vitamin. Bhujbal et al. [19] reported viscosity of matrix and the size of the beads are among factors in determining the strength of alginate-based encapsulation. Glucomannan is a non-ionic polysaccharide which unable to form a strong gel in the presence of divalent ions. This inability could lead to release the vitamin C from the bead. As a result, the efficiency of vitamin $\mathrm{C}$ encapsulation decreased in a higher ratio of glucomannan.

Meanwhile, increasing alginate was expected to improve the crosslink densities, enhance mechanical strength and compactness of the bead. However, the inverse result was observed in this study. Alginate was reported to have porosities [20]. Hence, the loss of vitamin $\mathrm{C}$ from the bead could be due to the porosity of alginate. Increasing alginate concentration provided more porosity which facilitated more loss of vitamin C.

In general, a combination of this alginate with glucomannan in the same ratio $(1: 1, g / g)$ created a positive interaction and resulted in the highest efficiency (95.82\%). This combination of the equal weight of polysaccharides allowed to form many hydrogen bonds which helped in entrapping vitamin C. The hydrogen bonds were not only formed intern of each molecule of glucomannan or alginate but also existed between these two polysaccharides. Zhen et al. [21] suggested a large number of hydrogen bonds could be created between glucomannan and alginate which mainly occurred between- $\mathrm{OH}$ on position $\mathrm{C} 6$ and $\mathrm{C} 3$ of mannose residues of glucomannan and $\mathrm{C}$ in position 2 and 3 of sodium alginate. The blending of glucomannan and alginate lead to a positive synergistic effect, because the chain segments of glucomannan surround the sodium alginate molecules spirally and irregularly, leading to the strong nonbonding intermolecular forces which tend to form stable conformations [21]. Hence, a similar ratio of combination excipient could contribute similar interaction in protecting and trapping vitamin $C$ which results in higher encapsulate efficiency.

Increasing concentration of vitamin $\mathrm{C}$ in the matrix affected the encapsulation efficiency. Higher vitamin C concentration tended to increase the efficiency until in a certain condition the capacity of the matrix to entrap vitamin $C$ reached the maximum. This could be due to unbalance interaction between the excipient and vitamin $C$ which resulted in decreasing the efficiency. The initial concentration of encapsulated vitamin $\mathrm{C}$ is shown in table 1 . A linear correlation between the active compound and the excipients was observed. Vitamin C is a polar organic compound which has hydroxyl groups on its structure. These groups could interact and form hydrogen bonding with the glucomannan-alginate, hence, increase the efficiency of higher vitamin C concentration. However, encapsulation using ratio glucomannan-alginate $1: 1(\mathrm{~g} / \mathrm{g})$ had a lower efficiency than that of other ratios when the concentration of vitamin $C$ was high (5\%). This higher concentration allowed to interrupt more hydrogen bonding of the matrix and reduced entrapped vitamin $\mathrm{C}$. The results suggested that the efficiency of encapsulation was not only relied on the excipient capability to entrap the amount of the vitamin $\mathrm{C}$, but also the internal synergism of the excipients and the external interaction between excipient and the active compound. Moreover, the interaction between the excipient and the crosslinking agent could also contribute to the efficiency of encapsulation.

Comparison of encapsulation preparation method on the efficiency of $3 \%$ of vitamin $\mathrm{C}$ was illustrated in fig. 1, which shows all the efficiencies of various encapsulation methods were higher than $80 \%$. There was no superior encapsulation method in term of efficiency. Overall, the first and second encapsulation method had better performance efficiency than that of the third method. The highest encapsulation efficiency (96.84\%) was performed using the first method of the ratio of glucomannan-alginate $3: 1(\mathrm{~g} / \mathrm{g})$. This highest in efficiency could be in relation with its viscosity. Wardhani et al. [18] reported this 3:1 ratio of glucomannan-alginate has the highest viscosity compare to other ratios.

In this work, the gelation process was conducted by dropping the excipient solution into the $\mathrm{CaCl}_{2}$ solution. Since alginate formed better gelation than glucomannan in $\mathrm{CaCl}_{2}$, hence coating the glucomannan encapsulation with alginate as the outer layer had helped to protect trapped vitamin C. When glucomannan was applied as an outer layer, higher alginate concentration has facilitated to trap more vitamin C in ratio $1: 3(\mathrm{~g} / \mathrm{g})$ of glucomannanalginate. This result corroborated with previous research which found that alginate contributed to increasing the encapsulation efficiency [12]. However, more rigid and higher mechanical strength of the matrix was produced when the concentration of alginate was much higher than that of glucomannan. This efficiency was because only a certain amount of vitamin C can be absorbed into the matrix of alginate [22] and resulted in higher efficiency.

\section{Vitamin C release}

Another objective of this work was to maintain a low concentration of vitamin $C$ existence in body liquid and less of the vitamin $C$ excesses was discharged from the body. It was expected that the encapsulant protects the vitamin $\mathrm{C}$ from the digesting process in the stomach which has pH 1.2. Moreover, the encapsulant should be able to deliver vitamin $\mathrm{C}$ to the small intestine where the vitamin is absorbed via a sodium-dependent active transport mechanism. The absorption efficiency gradually decreases at higher intakes of vitamin C [4].

The release performance of vitamin $\mathrm{C}$ encapsulation in 2-pHs is presented in fig. 2. In general, the release of vitamin $\mathrm{C}$ was $\mathrm{pH}-$ dependent. Higher concentrations of vitamin $\mathrm{C}$ were released at $\mathrm{pH}$ 1.2 (fig. 2-top) than those at pH 6.8 (fig. 2-bottom).

Fig. 3 illustrates the accumulation of released vitamin $\mathrm{C}$ at various vitamin $\mathrm{C}$ initial concentrations in which the releases were in line with release time. Higher concentration of the entrapped vitamin $C$ led to increasing the release rate at both pHs. Hence, a lower initial concentration of vitamin $\mathrm{C}$ was preferred to reduce the release rate. Unfortunately, accumulation of release of $1 \%$ vitamin $C$ was low in both $\mathrm{pHs}$ which were not a favor too. Encapsulation of $3 \%$ vitamin C showed the most compromise release in both pHs. This result shows that the excipient has a maximum loading capacity. Hence, in some points, increasing concentration of the active compound induced the release. This work suggested that $3 \%$ vitamin $\mathrm{C}$ could give a balance between high ability to trap and low release vitamin C. Among the ratios of glucomannan-alginate, the excipient of $3: 1(\mathrm{~g} / \mathrm{g}$ ) performed lower accumulation in $\mathrm{pH} 1.2$ but reverse accumulation observed in $\mathrm{pH}$ 6.8. Hence, this ratio was used in the next step of the study which focused on the encapsulation preparation methods. 

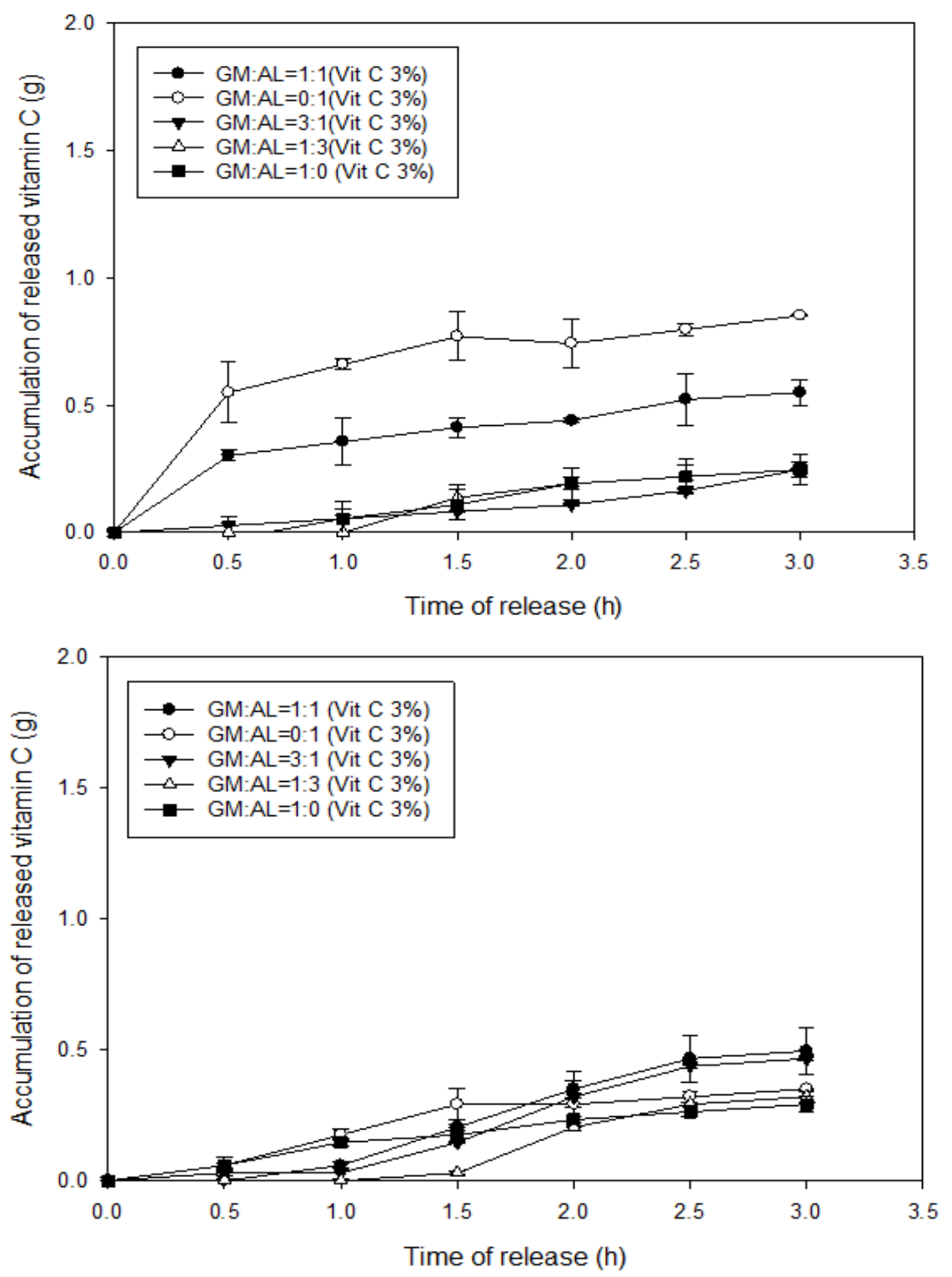

Fig. 2: Effect of various ratio of combined matrix encapsulation on the release profile of vitamin $\mathrm{C}$ at pH 1.2 (top) and pH 6.8 (bottom), ${ }^{*}$ results are expressed as mean $\pm \mathrm{SD}, \mathrm{n}=3$

Table 1: The amount of encapsulated vitamin C (g) per batch for various variables

\begin{tabular}{llll}
\hline The ratio of glucomannan-alginate (g/g) & Added vitamin C (g)/batch & Matrix preparation methods & Entrapment vitamin C (g)/batch \\
\hline $1: 1$ & 3 & $\left.(\mathrm{GM}+\mathrm{AL}+\mathrm{Vit} \mathrm{C})^{\mathrm{a}}\right)$ & $2.87 \pm 0.52$ \\
$0: 1$ & & & $2.75 \pm 0.48$ \\
$3: 1$ & & & $2.54 \pm 0.27$ \\
$1: 3$ & & & $2.02 \pm 0.58$ \\
$1: 0$ & 1 & & $2.02 \pm 0.36$ \\
$1: 1$ & & & $0.76 \pm 0.18$ \\
$0: 1$ & & & $0.76 \pm 0.20$ \\
$3: 1$ & 5 & & $0.73 \pm 0.12$ \\
$1: 1$ & & $(\mathrm{GM}+\mathrm{Vit} \mathrm{C})+\mathrm{AL} \mathrm{L}^{\mathrm{b})}$ & $4.31 \pm 0.78$ \\
$0: 1$ & & & $4.86 \pm 0.94$ \\
$3: 1$ & 3 & & $4.80 \pm 0.36$ \\
$1: 1$ & & & $2.78 \pm 0.36$ \\
$3: 1$ & & & $2.91 \pm 0.28$ \\
$1: 3$ & 3 & & $2.51 \pm 0.24$ \\
$1: 1$ & & & $2.54 \pm 0.33$ \\
$3: 1$ & & & $2.72 \pm 0.39$ \\
$1: 3$ & & & $2.87 \pm 0.43$ \\
\hline
\end{tabular}

a)First method: glucomannan, alginate, and vitamin $\mathrm{C}$ were mixed before beading, b)Second method: beads of glucomannan and vitamin $\mathrm{C}$ were coated with alginate, c)Third method: beads of alginate and vitamin $\mathrm{C}$ were coated with glucomannan, *results are expressed as mean $\pm \mathrm{SD}$, $\mathrm{n}=3$ 

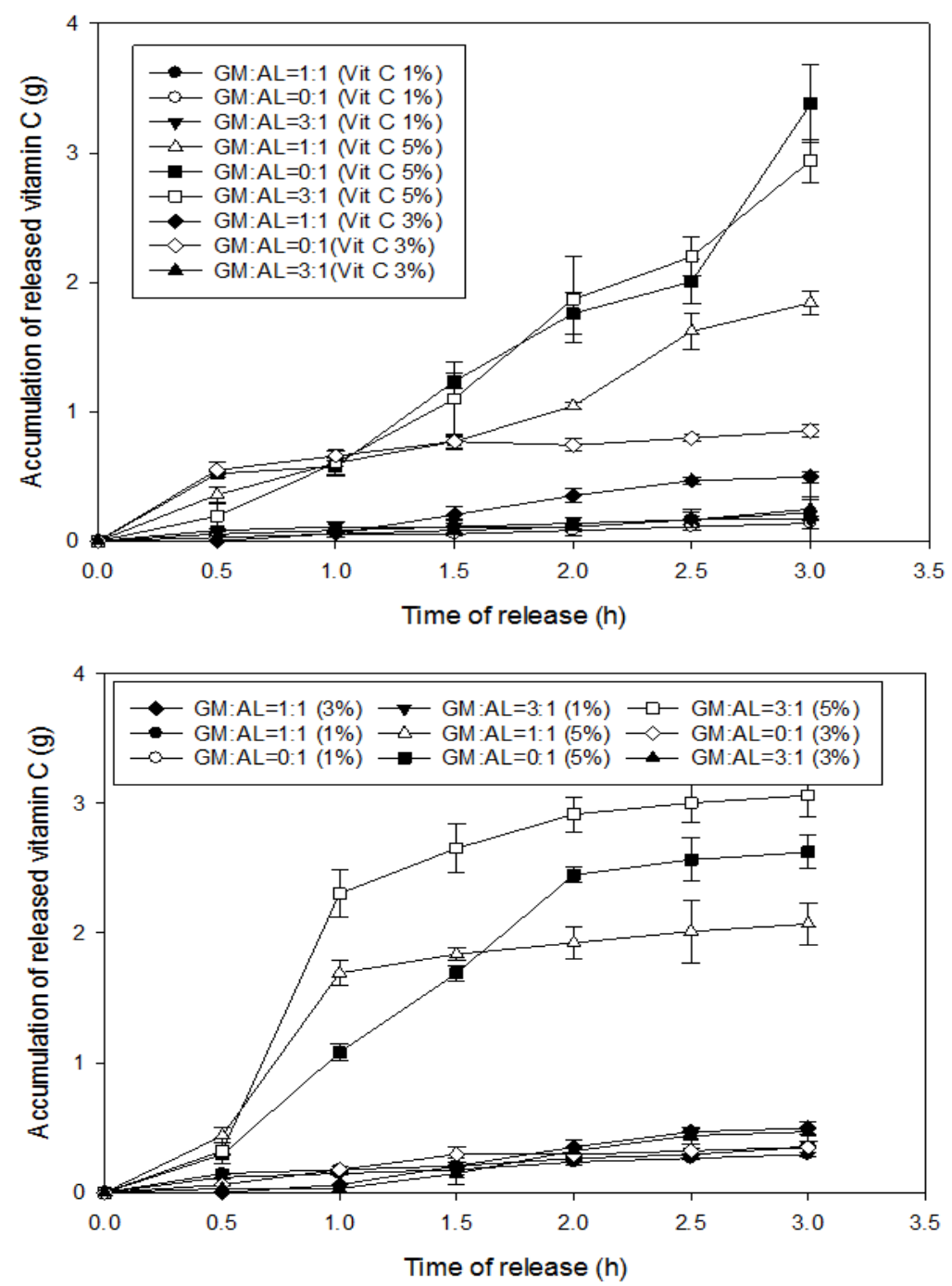

Fig. 3: Effect of concentration of $3 \%$ vitamin $\mathrm{C}$ on the release profile of vitamin $\mathrm{C}$ at pH 1.2 (top) and 6.8 (bottom), *Results are expressed as mean $\pm S D, n=3$

In this work, the encapsulation was applied to manage the release rate of vitamin $\mathrm{C}$ which controls by the $\mathrm{pH}$ of the simulated-digestion liquid. Fig. 3 shows the release rate of vitamin $\mathrm{C}$ from the matrix was faster in the intestine liquid-like than in the stomach, especially during the first two hour. The $1: 1(\mathrm{~g} / \mathrm{g})$ matrix of $3 \%$ vitamin $\mathrm{C}$ was the one that has a relative low release in both pHs. The use of a combination matrix could adversely affect to extend the period of the drug release profile. This combination allows forming the perfect interaction of glucomannan, alginate and vitamin $\mathrm{C}$ which mediated by hydrogen bonding to trap and control the release of vitamin $\mathrm{C}$.

Effect of encapsulation method on profile release of vitamin $\mathrm{C}$ at $\mathrm{pH}$ 1.2 (top) and pH 6.8 (bottom) is presented in fig. 4. The majority of the encapsulation method samples had low rate release in both $\mathrm{pHs}$, except for the samples of ratio 1:3 of the first method. The first method encapsulation had higher release rate in $\mathrm{pH} 1.2$ than that of $\mathrm{pH}$ 6.8. This high release seemed to relate with low efficiency as presented in fig. 1.

Alginate is less soluble in the acid liquid of stomach than in small intestine [23] which help in controlling release vitamin C. It consists of high content of the manuronate (M) group which is suitable in thickening applications, while the guluronate $(G)$ group is best for gelation [24]. However, a high concentration of alginate could cause difficulties for vitamin $\mathrm{C}$ to be released due to increasing gelation. Therefore, a combination of alginate and glucomannan can maintain in trapping and releasing water-soluble vitamin C. A lower release value was observed when glucomannan was applied as the outer layer of the matrix (the second preparation method). Previous research reported that sole glucomannan matrix shows a high value of control release [25].

\section{The functional groups}

The functional group comparison of alginate, glucomannan, vitamin $\mathrm{C}$ as well as their combinations is presented in fig. 5 . All matrixes materials have similar peaks in the range of 400-4000 $\mathrm{cm}^{-1}$, except those of the ascorbic acid. The peaks of glucomannan are in agreement with Chua et al. [26] and Wardhani et al. [27]. The native glucomannan has a wide band of the peak at $\sim 3400 \mathrm{~cm}^{-1}$ which attributed to $\mathrm{O}-\mathrm{H}$ stretching vibration. Some other peaks which also detected in glucomannan matrix in range of 1000-2000 $\mathrm{cm}^{-1}$ are carbonyl of acetyl groups $\left(\sim 1730 \mathrm{~cm}^{-1}\right)$ angular deformation of C-H $\left(\sim 1410\right.$ and $\left.1370 \mathrm{~cm}^{-1}\right)$ and C-O-C ether bond stretching $\left(\sim 1150 \mathrm{~cm}^{-1}\right.$ and $\left.\sim 1070 \mathrm{~cm}^{-1}\right)$. Chua et al. [26] also reported the presence of the peaks at $\sim 870 \mathrm{~cm}^{-1}$ and $\sim 800 \mathrm{~cm}^{-1}$ which attributed to $\beta$-glucosidic and $\beta$-mannosidic linkages in glucomannan.

The native alginate has also an $\mathrm{O}-\mathrm{H}$ stretching band $\left(\sim 3400 \mathrm{~cm}^{-1}\right), 0-$ $\mathrm{C}=0$ asymmetric stretching group $\left(\sim 1610 \mathrm{~cm}^{-1}\right), 0-\mathrm{C}=0$ asymmetric stretching $\left(\sim 1420 \mathrm{~cm}^{-1}\right)$, similar as reported by Huang et al. [28]. Gomez-Ordonez and Ruperez [29] reported the peaks of alginate sample also found at $\sim 1080 \mathrm{~cm}^{-1}$ and $\sim 1020 \mathrm{~cm}^{-1}$ bands which assigned to $\mathrm{C}-\mathrm{O}$ and $\mathrm{C}-\mathrm{C}$ stretching vibrations of pyranose ring and $\mathrm{C}-$ O-C glycosidic bonds. Moreover, Wang et al. [30] reported four peaks are detected in the fingerprint region of carbohydrates in alginate $\left(950-750 \mathrm{~cm}^{-1}\right)$. The weak peaks at $\sim 940$ and $\sim 930 \mathrm{~cm}^{-1}$ are assigned 
to $\mathrm{C}-\mathrm{O}$ stretching in pyranose rings and $\alpha$-bond in polysaccharide chains. Two other peaks at $\sim 875$ and $\sim 800 \mathrm{~cm}^{-1}$ are characteristic of guluronic and mannuronic acid groups, respectively [29].

Both Chua et al. [26] and Huang et al. [28] reported a- $\mathrm{CH}_{2}$ stretching vibration at $\sim 2900 \mathrm{~cm}^{-1}$ band was found in glucomannan and alginate. Interestingly, either lone glucomannan or lone alginate did not show a clear peak around $\sim 2900 \mathrm{~cm}^{-1}$ which assigned to $\mathrm{C}-\mathrm{H}$ group. This peak is observed only in the combination matrixes. The peak suggested that although each of glucomannan, alginate and vitamin C had unnoticeable absorbance of the stretching groups, this peak became stronger when these polysaccharides were combined.
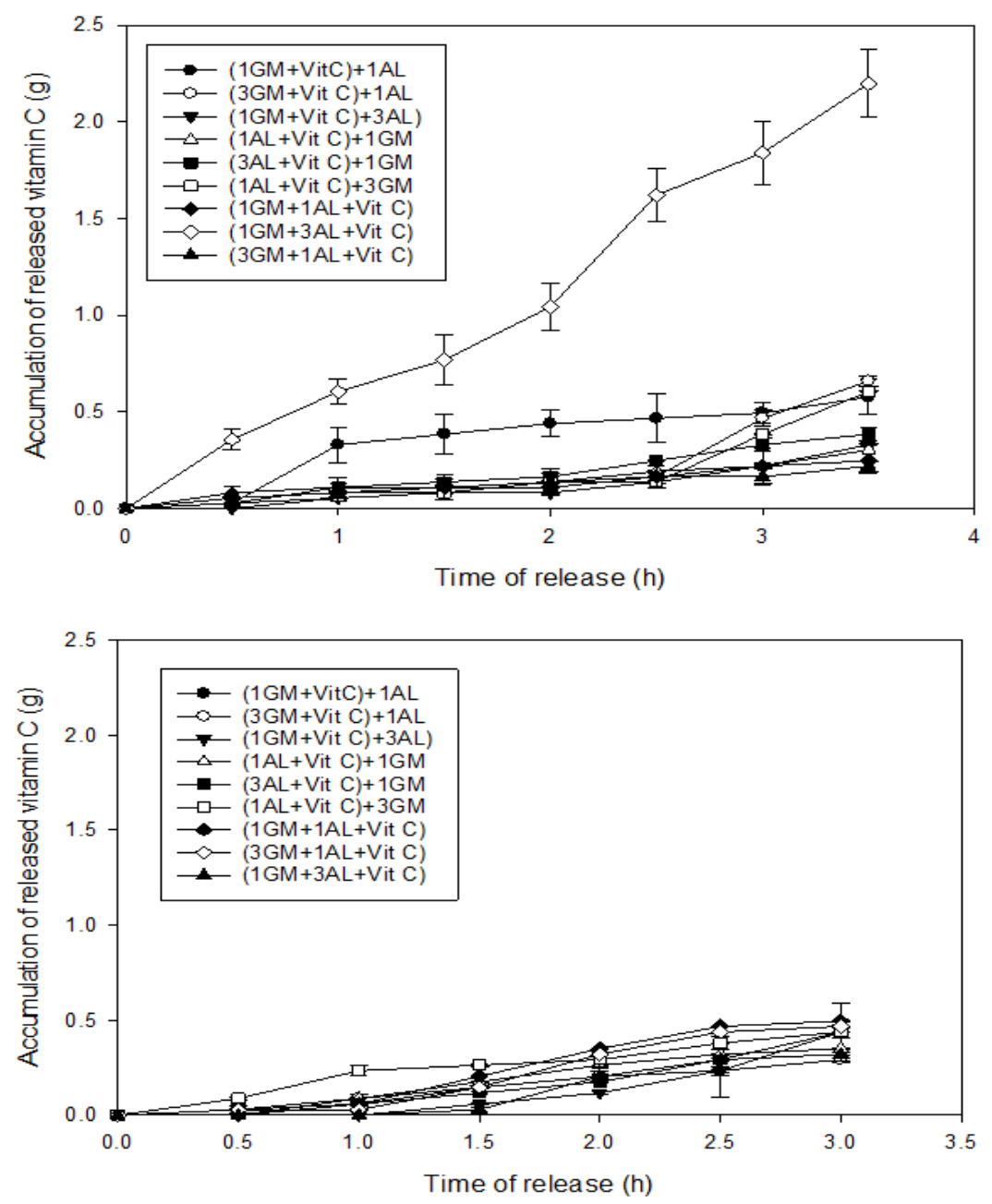

Fig. 4: Effect of encapsulation method of vitamin C on the release profile of vitamin $\mathrm{C}$ at pH 1.2 (top) and pH 6.8 (bottom), * Results are expressed as mean $\pm S D, n=3$

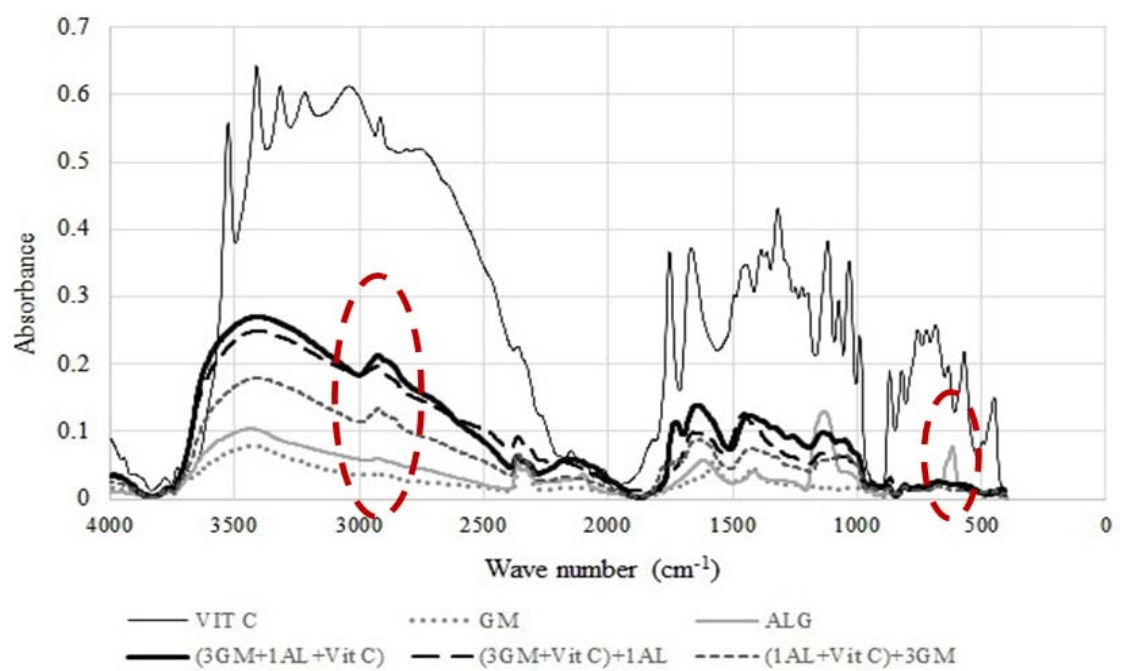

Fig. 5: Functional groups of various preparations of vitamin C encapsulation 

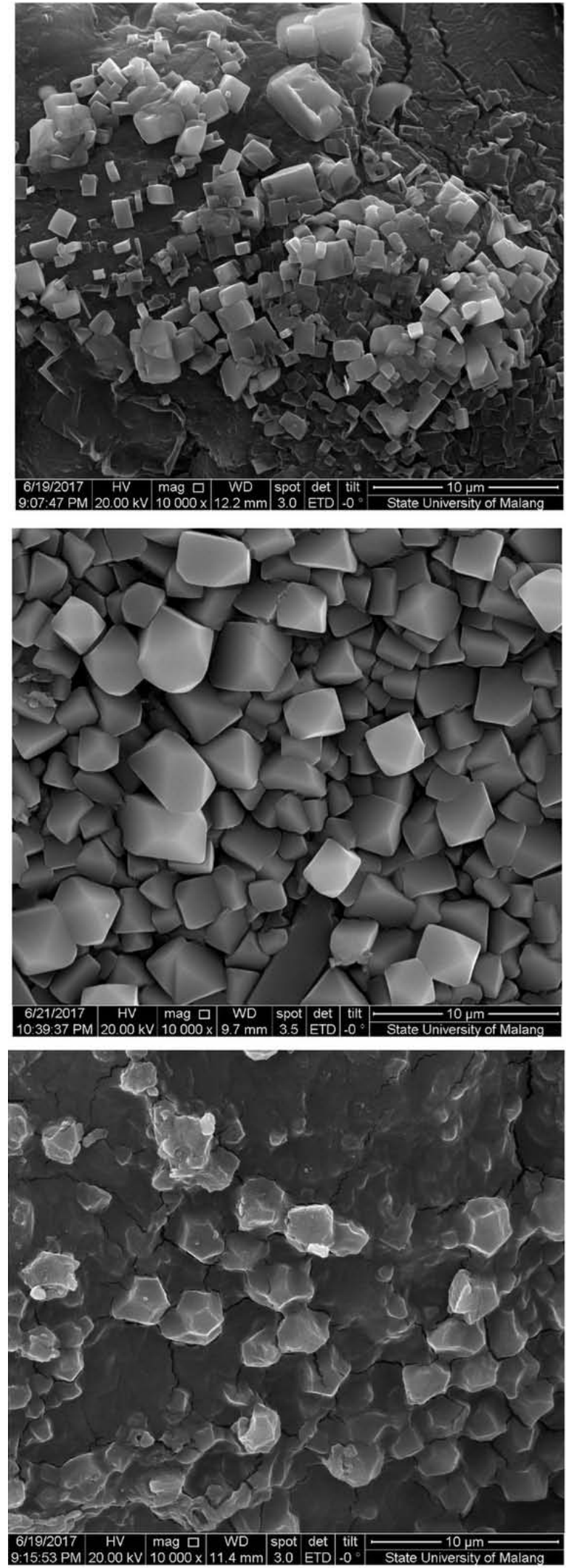

Fig. 6: Morphology of encapsulated 3\% vitamin C using various preparation methods: glucomannan and alginate $3: 1$, $\mathrm{g} / \mathrm{g}$ ) were blend together with the vitamin $\mathrm{C}$ (top), bead of three-parts of glucomannan and vitamin $C$ which coated with one-part alginate (middle), bead of one part of alginate and vitamin C which coated with three-parts of glucomannan (bottom)

\section{Bead morphologies}

The surface morphologies of encapsulate vitamin C prepared with three methods are described in fig. 6. The first method which blended glucomannan, alginate and vitamin $\mathrm{C}$ all together resulted in the bead surface covered by a group of rough square particles in some spots (fig. 6-top). When vitamin C was firstly encapsulated with glucomannan followed by alginate coating, the excipient mostly covered by the square separated particles (fig. 6-middle). Meanwhile, the fused particle covered the surface of the encapsulation when glucomannan was applied to cover the encapsulated vitamin C with alginate (fig. 6-bottom).

\section{CONCLUSION}

The most efficient encapsulation was prepared using a similar ratio of glucomannan and alginate $(1: 1, \mathrm{~g} / \mathrm{g})$ for encapsulate $3 \%$ vitamin C. This ratio showed lower released vitamin $\mathrm{C}$ in $\mathrm{pH} 1.2$ compared to that in $\mathrm{pH}$ 6.8. Coating the vitamin C-glucomannan bead with alginate showed better ability in encapsulating vitamin $\mathrm{C}$. The absorbance of all combination of excipient increased in most of the peaks of the functional groups. The surface profile of the bead depended on the encapsulation preparation method.

\section{ACKNOWLEDGMENT}

The authors would like to acknowledge PNBP DIPA UNDIP (University of Diponegoro, Semarang-Indonesia) for funding the research project through International Publication Research (RPI) scheme 2016. Ms Farida DH and Ms Kazenina MS were acknowledged for their lab works.

\section{AUTHORS CONTRIBUTIONS}

All the author have contributed equally

\section{CONFLICTS OF INTERESTS}

All authors have none to declare

\section{REFERENCES}

1. Alishahi A, Mirvaghefi A, Tehrani MR, Farahmand H, Shojaosadatic SA, Dorkoosh FA, et al. Shelf life and delivery enhancement of vitamin C using chitosan nanoparticles. Food Chem 2011;126:935-40.

2. Cho Y, Kim JT, Park HJ. Size-controlled self-aggregated N-acyl chitosan nanoparticles as a vitamin C carrier. Carbohydr Polym 2012;88:1087-92.

3. Gao X, Chen L, Xie J, Yin Y, Chang T, Duan Y, et al. In vitro controlled release of vitamin $\mathrm{C}$ from $\mathrm{Ca} / \mathrm{Al}$ layered double hydroxide drug delivery system. J Mater Sci Eng C 2014;39:56-60.

4. European Food Safety Authority (ESFA). Scientific opinion on dietary reference values for vitamin C. EFSA J 2013;3418:1-68.

5. McConnell EL, Fadda HM, Basit AW. Gut instincts: explorations in intestinal physiology and drug delivery. Int J Pharm 2008;364:213-26.

6. Zhang C, Chen J, Yang FQ. Konjac glucomannan, a promising polysaccharide for OCDDS. Carbohydr Polym 2014;104:175-81.

7. Jeganathan B, Prakya V. Preparation and evaluation of floating extended release matrix tablet using combination of polymethacrylates and polyethylene oxide polymers. Int J Pharm Pharm Sci 2014;6:584-92.

8. Rojas J, Ciro Y, Zapata S. Chitosan as a potential microencapsulation carrier for ascorbic acid stabilization in heterodisperse systems. Int J Pharm Pharm Sci 2015;7:69-72.

9. Liu W, Tian M, Kong y, Lu J, Li N, Han J. Multilayered vitamin C nanoliposomes by self-assembly of alginate and chitosan: longterm stability and feasibility application in mandarin juice. LWT 2017;75:608-15.

10. Gao S, Nishinari K. Effect of deacetylation rate on gelation kinetics of konjac glucomannan. Colloids Surf B 2004;38:241-59.

11. Alonso Sande M, Teijeiro D, Remunan Lopez C, Alonso MJ. Glucomannan, a promising polysaccharide for biopharmaceutical purposes. Eur J Pharm Biopharm 2009;72:45362.

12. Wang K, He Z. Alginate-konjac glucomannan-chitosan beads as a controlled release matrix. Int J Pharm 2002;244:117-26. 
13. Desai KG, Liu C, Park HJ. Characteristics of vitamin C encapsulated tripolyphosphate-chitosan microspheres as affected by chitosan molecular weight. J Microencap 2006;23:79-90.

14. Jackson JA, Wong K, Krier C, Riordan HD. Screening for vitamin $\mathrm{C}$ in the urine: Is it clinically significant. J Orthomolecular Med 2005;20:259-61.

15. Naidu KA. Vitamin $\mathrm{C}$ in human health and disease is still a mystery? An overview. Nutr J 2003;2:1-10.

16. Yang $\mathrm{D}$, Yuan $\mathrm{Y}$, Wang $\mathrm{L}$, Wang $\mathrm{X}, \mathrm{Mu} \mathrm{R}$, Pang J, et al. A review on konjac glucomannan gels: microstructure and application. Int J Mol Sci 2017;18:2250-68.

17. Bastos DS, Araujo KGL, Leao MHMR. Ascorbic acid retaining using a new calcium alginate-capsule based edible film. J Microencapsulation 2009;26:97-103.

18. Wardhani DH, Hapsari FD, Suryana KM, Aryanti N, Cahyono H. Physicochemical properties of glucomannan-alginate as vitamin c excipient. Evergreen 2018;5:6-10.

19. Bhujbal SV, Paredes Juarez GA, Niclou SP, Vos PD. Factors influencing the mechanical stability of alginate beads applicable for immunoisolation of mammalian cells. J Mech Behav Biomed Mater 2014;37:196-208.

20. Mohamed HN, Mustafa S, Fitrianto A, Manap YA. Optimization and characterization of calcium alginate/konjac glucomannan beads as an oral protein drug delivery system. Int J Curr Pharm Clin Res 2015;5:94-105.

21. Zhen M, Jie P, Mei Ling L, Bing Qing X, Han C, Jing Ling C. Quantum mechanical analysis of sodium alginate effect on the konjac glucomannan. Chin J Struct Chem 2015;34:1187-96.

22. Lotfipour F, Mirzaeei S, Maghsoodi M. Evaluation of the effect of $\mathrm{CaCl}_{2}$ and alginate concentrations and hardening time on the characteristics of lactobacillus acidophilus loaded alginate beads using response surface analysis. Adv Pharm Bull 2012;2:71-8.

23. Hamed S, Ayob FA, Alfatama M, Doolaanea AA. Enhancement of the immediate release of paracetamol from alginate beads. Int J Appl Pharm 2017;9:47-51.

24. Ahmad Z, Khuller GK. Alginate-base sustained release drug delivery system for tuberculosis. Exp Opin Drug Delivery 2008;5:1323-34.

25. Liang H, Ye T, Zhou B, Li J, He L, Li Y, et al. Fabrication of gastric floating controlled release tablet based on konjac glucomannan. Food Res Int 2015;72:47-53.

26. Chua M, Chan K, Hocking TJ, Williams PA, Perry CJ, Baldwin TC. Methodologies for the extraction and analysis of konjac glucomannan from corms of Amorphophallus konjac K. Koch. Carb Pol 2012;87:2202-10.

27. Wardhani DH, Nugroho F, Muslihudin, Aryanti N. Application of response surface method on purification of glucomannan from Amorphophallus oncophyllus by using 2-propanol. Sci Study Res: Chem Chem Eng Biotech Food Ind 2016;17:63-74.

28. Huang H, Grün IU, Ellersieck M, Clarke AD. Measurement of total sodium alginate in restructured fish products using fourier transform infrared spectroscopy. EC Nutr 2017;11:3345.

29. Gomez Ordonez E, Ruperez P. FTIR-ATR spectroscopy as a tool for polysaccharide identification in edible brown and red seaweeds. Food Hydrocol 2011;25:1514-20.

30. Wang $\mathrm{Y}$, Mortimer M, Chang $\mathrm{CH}$, Holden PA. Alginic acid-aided dispersion of carbon nanotubes, graphene, and boron nitride nanomaterials for microbial toxicity testing. Nanomaterials 2018;8:1-22. 